\title{
Revisiting Mars and Venus: understanding gender differences in critical illness
}

\author{
Michael C Reade', Sachin Yende ${ }^{2 *}$ and Derek C Angus \\ See related research by Nachtigall et al., http://ccforum.com/content/15/3/R151
}

\begin{abstract}
Understanding the nature and biological basis of gender-determined differences in risk of and outcome from infection might identify new therapeutic targets, allow more individualised treatment, and facilitate better risk prediction and application of healthcare resources. Gender differences in behaviours, comorbidities, access to healthcare and biology may result in differences in acquiring infection, or in response to infection once acquired. Some studies have reported higher male susceptibility to infection, and higher risk of death with sepsis, but others have found the opposite effect. The explanation for this disagreement is probably that different studies have included patients at different stages on the continuum from infectious agent exposure to death or recovery. Studying sufficient patient numbers to explore this entire continuum while accounting for heterogeneity in type of infection and comorbidity is difficult because of the number of patients required. However, if true gender effects can be identified, examination of their biological or psychosocial causes will be warranted.
\end{abstract}

Much effort has been expended identifying factors associated with sepsis susceptibility, prognosis and response to treatment. As with other risk factors, understanding gender-determined differences in response to infection might highlight new therapies or identify patients especially likely to respond to a particular treatment. Understanding the effect of gender in infection is therefore important. The paper by Nachtigall and colleagues in the previous issue of Critical Care is the latest contribution to this topic [1].

*Correspondence: yendes@upmc.edu

${ }^{2}$ CRISMA Center, Department of Critical Care Medicine, University of Pittsburgh,

Pittsburgh, PA 15261, USA

Full list of author information is available at the end of the article
Men and women differ in a number of respects that, overall, result in men dying earlier. Men have more highrisk behaviours such as smoking and activities leading to trauma. Men acquire chronic diseases earlier [2], in part due to lifestyle choices but also due to biological differences that are far from fully defined [3]. Men with some [4], but not other [5], actue illnesses tend to present later to medical care. Men receive more aggressive medical interventions once in hospital [6]. Sex hormones may modulate response to infectious agents [7]. Menstruation is a repeated acute inflammatory state that might modify response to infection. Cellular mosaicism in women may influence immune response [8]; for example, by attenuating the effect of polymorphisms in X-linked inflammatory genes such as IRAK-1 [9]. Each of these factors probably influences response to infection.

Many observational studies have attempted to identify gender differences in outcome from infection. Some studies have found that men are more susceptible to infection $[2,10]$ and that men are more likely to die once an infection occurs $[4,11,12]$. Other studies, however, have found the opposite effect $[13,14]$. Much confusion is due to oversimplification of the progression from infectious agent exposure to death. Rather than a single event, this progression represents a number of stages of illness, and men and women may progress through these stages differently. For instance, a person exposed to an infectious agent first has a risk of that agent causing localised disease, probably related to inflammatory and immunological priming. Second, once the organism has taken hold, the risk of developing a systemic inflammatory response - sepsis - is likely to be determined by a different constellation of factors. Once sepsis occurs, the risk of progression to organ dysfunction - or severe sepsis - is probably related to still more factors, including comorbidity. Last, the risk of death is influenced by the ability and willingness of the patient to access organ support, and their physiological reserve. Observational studies recruit patients in varying phases of this continuum, leading to considerable confusion.

The paper by Nachtigall and colleagues reports that, in a largely surgical adult ICU cohort of 709 patients, ICU 
mortality was similar between men and women [1]. Importantly, all of these patients were receiving antibiotics either for surgical prophylaxis or for treatment of septic shock. Patients therefore entered the study at a mixture of points on the above continuum. In the 327 patients who had sepsis, being female nearly doubled the risk of death, independent of differences in age, intensity of therapeutic interventions, source of infection, organism and presence of shock. In the entire patient cohort (46\% of whom were also in the sepsis group), however, gender had no influence on ICU mortality. Overall, then, among patients requiring antibiotics, it seems that either the beneficial and detrimental effects of being female cancelled one another or gender had little effect. Arguing for some effect of gender is the convincingly higher female sepsis mortality.

Further to this observation, Nachtigall and colleagues' paper contains a striking finding not discussed in the manuscript. Of 400 males in the cohort, 197 (49\%) developed sepsis, compared with only 130 of 309 (42\%) females, a difference that nearly reaches significance $(P=0.06)[1]$. Whether this difference would remain or would be adjusted away in multivariable analyses remains speculative. However, it appears plausible to conclude that, if exposed to infection, men are more likely to develop sepsis - as, indeed, other studies have found $[2,10]$. Knowledge of the infection continuum makes the apparent contradiction between this observation and that of increased female mortality in the presence of sepsis more easily understood. Prior studies suggest that the observed gender differences in this study may be due to differences in the immune response [4], perhaps mediated by oestrogen levels rather than gender per se [15]. As the authors note, however, such explanations of the effect of gender in their cohort are speculative.

The study faced several challenges in isolating the effect of gender in critically ill patients. First, studies that recruit a heterogeneous population of patients must adjust for potential confounding. The study did adjust for factors that in univariate or backwards stepwise multivariate analysis were significant predictors. However, women were more likely than men to be immunosuppressed, and this difference was larger among those who developed severe sepsis (2.5-fold higher risk among women). While not statistically significant predictors, such differences may still confound the association between gender and mortality. Studies that recruit heterogeneous populations should have a sufficiently large sample size to ensure that results are robust. Second, the authors report data regarding ICU mortality. Although men with sepsis had higher risk of developing septic shock, the length of ICU stay was similar and ICU mortality was lower among men. Many more men than women had undergone cardiac surgical procedures. If cardiac surgical patients were discharged from the ICU to a high-dependency ward earlier than other types of patient, as is true in many hospitals, their ICU mortality may be artificially lowered. Whether the higher mortality for women persists at 28 or 90 days remains unclear.

At first glance, it is reassuring that Nachtigall and colleagues found almost no gender differences in quality of care. However, perhaps men should have received more resources to reduce their incidence of sepsis, or women should have been treated more aggressively to reduce their mortality once sepsis occurred? If a strategy to reduce transition from infection to sepsis was more effective than one to treat sepsis once established (or vice versa), an alternative strategy would be to aim for optimisation (rather than equalisation) of mortality in men and women. Ethical questions regarding resource allocation with respect to gender remain theoretical while the mechanisms underlying the observed disparities are not understood. If this changes with further work, as might be hoped, such questions of equality will need to be addressed.

\section{Competing interests}

The authors declare that they have no competing interests.

\section{Author details}

'Department of Intensive Care Medicine, Austin Hospital and University of Melbourne, Melbourne, VIC 3084, Australia. ${ }^{2}$ CRISMA Center, Department of Critical Care Medicine, University of Pittsburgh, Pittsburgh, PA 15261, USA.

Published: 8 August 2011

\section{References}

1. Nachtigall I, Tafelski S, Rothbart A, Kaufner L, Schmidt M, Tamarkin A, Kartachov M, Zebedies D, Trefzer T, Wernecke KD, Spies C: Gender-related outcome difference is related to course of sepsis on mixed ICUs: a prospective, observational clinical study. Crit Care 2011, 15:R151.

2. Klein SL: The effects of hormones on sex differences in infection: from genes to behavior. Neurosci Biobehav Rev 2000, 24:627-638.

3. Leinwand LA: Sex is a potent modifier of the cardiovascular system. $J$ Clin Invest 2003, 112:302-307.

4. Reade MC, Yende S, D'Angelo G, Kong L, Kellum JA, Barnato AE, Milbrandt EB, Dooley C, Mayr FB, Weissfeld L, Angus DC: Differences in immune response may explain lower survival among older men with pneumonia. Crit Care Med 2009, 37:1655-1662.

5. Kaul P, Armstrong PW, Sookram S, Leung BK, Brass N, Welsh RC: Temporal trends in patient and treatment delay among men and women presenting with ST-elevation myocardial infarction. Am Heart J 2011, 161:91-97.

6. Valentin A, Jordan B, Lang T, Hiesmayr M, Metnitz PG: Gender-related differences in intensive care: a multiple-center cohort study of therapeutic interventions and outcome in critically ill patients. Crit Care Med 2003, 31:1901-1907.

7. Angstwurm MW, Gaertner R, Schopohl J: Outcome in elderly patients with severe infection is influenced by sex hormones but not gender. Crit Care Med 2005, 33:2786-2793.

8. Migeon BR: The role of $\mathrm{X}$ inactivation and cellular mosaicism in women's health and sex-specific diseases. JAMA 2006, 295:1428-1433.

9. Toubiana J, Courtine E, Pene F, Viallon V, Asfar P, Daubin C, Rousseau C, Chenot C, Ouaaz F, Grimaldi D, Cariou A, Chiche JD, Mira JP: IRAK1 functional genetic variant affects severity of septic shock. Crit Care Med 2010, 38:2287-2294

10. Wichmann MW, Inthorn D, Andress HJ, Schildberg FW: Incidence and mortality of severe sepsis in surgical intensive care patients: the influence of patient gender on disease process and outcome. Intensive Care Med 2000, 26:167-172. 
11. Angus DC, Linde-Zwirble WT, Lidicker J, Clermont G, Carcillo J, Pinsky MR: Epidemiology of severe sepsis in the United States: analysis of incidence, outcome, and associated costs of care. Crit Care Med 2001, 29:1303-1310.

12. Kaplan V, Angus DC, Griffin MF, Clermont G, Scott WR, Linde-Zwirble WT: Hospitalized community-acquired pneumonia in the elderly: age- and sex-related patterns of care and outcome in the United States. Am J Respi Crit Care Med 2002, 165:766-772.

13. Crabtree TD, Pelletier SJ, Gleason TG, Pruett TL, Sawyer RG: Genderdependent differences in outcome after the treatment of infection in hospitalized patients. JAMA 1999, 282:2143-2148.
14. Eachempati SR, Hydo L, Barie PS: Gender-based differences in outcome in patients with sepsis. Arch Surg 1999, 134:1342-1347.

15. Dossett LA, Swenson BR, Heffernan D, Bonatti H, Metzger R, Sawyer RG, May AK: High levels of endogenous estrogens are associated with death in the critically injured adult. J Trauma 2008, 64:580-585.

doi:10.1186/cc10319

Cite this article as: Reade MC, et al:: Revisiting Mars and Venus:

understanding gender differences in critical illness. Critical Care 2011, 15:180. 